\title{
HUBUNGAN KINERJA KELOMPOK TANI DENGAN PENDAPATAN USAHATANI PADI SAWAH (Oryza sativa, L.) DI KECAMATAN TUKDANA, KABUPATEN INDRAMAYU
}

\author{
Mohammad Fahmariza ${ }^{1}$, Entus Hikmana ${ }^{2}$ Tohidin $^{3}$ \\ 1,2,3 Program Studi Agribisnis, Fakultas Pertanian, Universitas Wiralodra \\ Email : fahmariza121@gmail.com², entushikmana@gmail.com² ${ }^{2}$ tohidin@gmail.com
}

\begin{abstract}
ABSTRAK
Penelitian ini bertujuan untuk mengetahui kinerja kelembagaan kelompok tani di Kecamatan Tukdana Kabupaten Indramayu dan mengetahui tingkat hubungan kinerja kelembagaan kelompok tani terhadap pendapatan usahatani padi sawah (Oryza sativa, L.) di Kecamatan Tukdana Kabupaten Indramayu. Objek penelitian ini adalah kelompok tani di Kecamatan Tukdana Kabupaten Indramayu sebanyak 10 kelompok tani. Metode yang digunakan dalam penelitian ini adalah survei. Desain penelitian yang digunakan yaitu metode Survei Explanatori. Terdapat 50 populasi (kelompok tani) penentuan sampel dilakukan secara sengaja (Purposive) mengakibatkan penelitian ini memiliki 40 responden terdiri dari 10 kelompok tani masing-masing ketua, sekertaris, bendahara dan anggota kelompok tani tersebut untuk mengetahui kinerja dan pendapatannya. Teknik pengambilan data dilakukan observasi dan wawancara. Analisi yang digunakan dalam penelitian ini untuk menguji hubungan keeratan antara variabel kinerja kelompok tani dengan pendapatan usahatani, menggunakan analisis korelasi Product moment dengan menggunakan alat bantu aplikasi SPSS 20. Kinerja kelompok di Kecamatan Tukdana Kabupaten Indramayu sudah cukup baik, sebagian besar kinerja kelompok tani adalah tergolong klasifikasi cukup dengan skor 246 - 455, yaitu 8 kelompok tani sudah tergolong klasifikasi cukup dan 2 kelompok tani tergolong klasifikasi kurang (245). Hasil dari analisis diperoleh angka koefisien korelasi sebesar 0,678 artinya tingkat kekuatan hubungan (korelasi) antara variabel kinerja kelompok tani dengan pendapatan adalah kuat $(0,600-0,799)$. Dengan nilai sebesar 0,678 dapat menggambarkan sejauhmana keeratan hubungan antara variabel kinerja kelompok tani dengan pendapatan usahatani padi sawah dengan nilai $67,8 \%$. Jadi hubungan antara kinerja kelompok tani dengan pendapatan padi sawah di Kecamatan Tukdana Kabupaten Indramayu dapat dinyatakan positif maka hubunganya searah.
\end{abstract}

Kata kunci : Kinerja, Kelompok tani, Pendapatan, Usahatani

\section{I.PENDAHULUAN}

Sumberdaya alam dan manusia di Kabupaten Indramayu secara jumlah bilamana dikelola dan diberdayagunakan dinilai telah cukup memadai, namun pengorganisasian sumberdaya ekonomi, terutama keorganisasian ekonomi di pedesaan, masih jauh dari memadai. Oleh sebab itu bisa dimengerti jika berbagai jenis program pembangunan pertanian di pedesaan yang selama ini dijalankan, terutama karena lebih menekankan pada dimensi budaya material, masih belum memberikan dampak yang cukup positif terhadap kebangkitan dan kemandirian perekonomian pedesaan.

Hubungan antara pemacuan produksi dengan penguatan dan kemandirian ekonomi di pedesaan selama ini cenderung dinilai sebagai hubungan yang linier atau searah. Kenyataan banyak diperoleh bukti bahwa hubungan tersebut tidak selamanya sejajar. Keberhasilan pertumbuhan produksi hasil pertanian khususnya padi sawah, bila dilihat dari bingkai keberhasilan pembangunan, terutama dari segi pemerataan atau keadilan ekonomi di pedesaan, maka hal itu masih mengundang banyak pertanyaan (Syahyuti, 2009).

Berbagai permasalahan yang mempengaruhi perekonomian pedesaan tersebut, kelembagaan merupakan salah satu faktor yang perlu dicermati untuk mengetahui kelembagaan yang perlu mendapatkan prioritas berkaitan dengan upaya meningkatkan kualitas hidup rumah tangga petani. Pemahaman terhadap konsep lembaga atau kelembagaan (institusi) sejauh ini lebih terpaku pada organisasi, baik organisasi formal maupun organisasi nonformal. Istilah kelembagaan (institutional) dewasa ini lebih sering digunakan untuk makna yang sama dengan "keorganisasian". Padahal terdapat 
perbedaan dan hubungan antara kelembagaan dan organisasi; dimana kelembagaan lebih menekankan pada kompleks nilai (rule), dan organisasi menitikberatkan pada jaringan peran (role) (Syahyuti, 2007).

Menurut BPP (Balai Penyuluh Pertanian) Kecamatan Tukdana Tahun 2018, keadaan kelompok tani di Kecamatan Tukdana sudah tergolong baik, ditunjang dari segi keadaan kelompok tani tersebut. Hal ini diperkuat dengan data yang diperoleh penulis untuk menunjang penelitian yang sedang dilakukan. Selama ini di desa selain kelompok tani telah ada seperangkat lembaga yang muncul dan timbul dari inisiatif masyarakat setempat untuk memenuhi kebutuhan hidupnya, seperti ulu-ulu, bengkok, kasikepan, titisara, sedekah bumi dan sebagainya. Umumnya kelembagaan lokal tersebut masih berupa kumpulan suatu kompleks nilai, sehingga belum memiliki jaringan peran yang nyata dan bersifat sangat tradisional dengan berbagai kekurangan-kekurangan yang ada dari segi organisasi modern. Padahal di sisi lain pemerintah sangat memerlukan lembaga yang adaftif untuk menjadi wadah atau saluran pembangunan dalam mempercepat pembangunan di pedesaan. Saat ini potret petani dan kelompok petani khususnya di Kecamatan Tukdana Kabupaten Indramayu, masih belum sebagaimana yang diharapkan. Diantaranya permasalahan yang masih melekat pada sosok petani dan kelompok petani adalah: (a) masih minimnya wawasan dan pengetahuan petani terhadap masalah manajemen produksi maupun jaringan pemasaran; (b) belum terlibatnya secara utuh petani dalam kegiatan agribisnis, dimana aktivitas petani masih terfokus pada kegiatan produksi (on farm) dan (c) peran dan fungsi kelompok petani sebagai wadah organisasi petani belum berjalan secara optimal. Penelitian ini bertujuan untuk mengetahui kinerja kelembagaan kelompok tani di Kecamatan Tukdana Kabupaten Indramayu dan Mengetahui tingkat hubungan kinerja kelembagaan kelompok tani terhadap pendapatan usahatani padi sawah (Oryza sativa, L.) di Kecamatan Tukdana Kabupaten Indramayu.

\section{II.METODE PENELITIAN}

Objek penelitian ini adalah 10 kelompok tani yang aktif untuk mengukur kinerja dan pendapatan masing-masing ketua kelompok, sekertaris, bendahara, dan anggota kelompok tani di Kecamatan Tukdana Kabupaten Indramayu. Metode yang digunakan dalam peneliatan ini adalah metode Survei. Desain penelitian yang digunakan yaitu metode Survei Explanatori. Variabel penelitian baik variabel pengaruh (independent variable) maupun variabel yang dipengaruhi (dependent variabel) dengan berbagai indikator yang menjelaskan variabel tersebut serta skalanya yang terkait dengan pemecahan masalah. Jenis data yang dikumpulkan dalam penelitian ini adalah data primer dan data skunder. Dalam penelitian ini terdapat 50 populasi kelompok tani yang ada di Kecamatan Tukdana Kabupaten Indramayu. Dan kelompok yang masih eksis keaktifannya terdapat 10 kelompok. Oleh karena itu sampel yang terpilih, diambil 10 sampel kelompok tani secara sengaja ( purposive) yang dianggap layak dan masih eksis keaktifannya. Teknik pengambilan data yang dilakukan pada penelitian ini yaitu dengan cara observasi, wawancara dan studi pustaka. anaisis data yang digunakan dalam penelitian ini adalah analisis Korelasi Product Moment (KMP), analisi korelasi yang digunakan dalam penelitian ini adalah untuk menguji hubungan keeratan antara variabel kinerja kelompok tani dengan pendapatan usahatani.

\section{III.HASIL DAN PEMBAHASAN}

Keadaan kelompok tani di Kecamatan Tukdana Kabupaten Indramayu sudah cukup baik dalam segi keaktifan kelompok. Hal ini dapat diukur dengan adanya kelompok tersebut dan kegiatankegiatan yang berkelanjutan. Karena beberapa kendala yang ada mulai dari kelompok yang sekedar nama sampai dengan tidak aktif dari segi kegiatan maupun anggotanya, menyebabkan total dari 50 kelompok tani yang ada di Kecamatan Tukdana Kabupaten Indramayu penulis menyimpulkan ada 10 kelompok (aktif) yang telah diukur dari dua aspek tersebut. Ciri-ciri kelompok tani yang aktif adalah adanya kegiatan rutin dan berkelanjutan, adanya kolompok tersebut tidak sekedar nama saja (data dari BPS). Terdata yang sudah di ketahui ada 10 kelompok (aktif) terdiri dari masing-masing 10 ketua kelompok yang akan diberikan kuisioner untuk mengetahui kinerjanya. Ketua kelompok mewakili kinerja dari keseluruhan anggora karena sebagian besar dipengaruhi oleh ketua kelompok tani tersebut 
Tabel 1 skor dari kinerja kelompok tani

\begin{tabular}{|c|c|c|c|c|c|c|c|c|}
\hline No. & Nama & Kinerja 1 & Kinerja 2 & Kinerja 3 & Kinerja 4 & Kinerja 5 & Total & Keterangan \\
\hline 1 & $\begin{array}{l}\text { Tengah } \\
\text { Mekar }\end{array}$ & 70 & 45 & 140 & 25 & 70 & 350 & $\mathrm{~L}$ \\
\hline 2 & Gempol & 50 & 40 & 100 & 25 & 30 & 245 & $\mathrm{P}$ \\
\hline 3 & Sri Murni 3 & 60 & 45 & 110 & 25 & 70 & 310 & $\mathrm{~L}$ \\
\hline 4 & Panca Kerta & 60 & 45 & 110 & 25 & 70 & 310 & $\mathrm{~L}$ \\
\hline 5 & Sri Murni 2 & 70 & 45 & 130 & 25 & 70 & 340 & $\mathrm{~L}$ \\
\hline 6 & Dewi Sri & 70 & 45 & 130 & 25 & 70 & 340 & $\mathrm{~L}$ \\
\hline 7 & $\begin{array}{l}\text { Karang } \\
\text { Moncol }\end{array}$ & 60 & 45 & 110 & 25 & 70 & 310 & $\mathrm{~L}$ \\
\hline 8 & Mekar Jaya & 60 & 45 & 120 & 25 & 70 & 320 & $\mathrm{~L}$ \\
\hline 9 & Ranca Bango & 70 & 40 & 130 & 25 & 70 & 335 & $\mathrm{~L}$ \\
\hline 10 & Suka Mukti & 50 & 40 & 100 & 25 & 30 & 245 & $\mathrm{P}$ \\
\hline
\end{tabular}

Total skor dari kinerja kelompok tani yang diukur dengan beberapa indikator kegiatan yang meliputi merencanakan kegiatan, Kemampuan mengorganisasikan, kemampuan melaksanakan kegiatan, kemampuan melakukan pengendalian dan pelaporan, kemampuan pengembangan kepemimpinan kelompok, sebagian besar kinerja kelompok tani adalah lanjut dengan nilai 246 - 455, yaitu 8 petani atau responden sudah tergolong lanjut dan 2 petani/responden tergolong pemula $(<=245)$. Artinya kinerja kelompok tani di Kecamatan Tukdana Kabupaten Indramayu sudah tergolong baik dalam melakukan usahanya dan dapat memenuhi permintaan pasar.

Tabel 2 biaya produksi yang dikeluarkan oleh petani

\begin{tabular}{clc}
\hline \multicolumn{1}{c}{ Biaya } & Rata-rata (Rp) \\
\hline 1 & Biaya variabel : & \\
& Bibit & 361,521 \\
& Pupuk Urea & 202,535 \\
& Pupuk SP36 & 140,592 \\
& Pupuk NPK Ponska & 458,704 \\
& Petroganik & 124,748 \\
& Pestisida / Insektisida & $1,233,652$ \\
& Upah Tenaga kerja & $6,024,014$ \\
\hline Total Biaya & $8,545,767$ \\
\hline 2 & Biaya Tetap : & 167,600 \\
& Penyusutan alat & 189,944 \\
& Air & 167,882 \\
& Pajak & 525,425 \\
\hline & Total Biaya & $9,069,792$ \\
\hline
\end{tabular}

Rata-rata biaya produksi total yang dikeluarkan oleh petani adalah sebesar Rp. 9.069.792,00 dalam satu kali produksi. Biaya yang paling terbesar yang dikeluarkan petani adalah biaya variabel, yaitu upah tenaga kerja sebesar Rp. 6.024.014,00 dalam satu kali produksi dimana dalam biaya tenaga kerja ini terbagi atas beberapa pekerjaan yaitu pengolahan lahan, penanaman, pemupukan dan penyiangan 1, pemupukan dan penyiangan 2, penyemprotan, panen dan pasca panen, dan penjemuran. Rata-rata harga gabah Rp. 5.390,00 sedangkan rata-rata hasil produksi gabah di Kecamatan Tukdana adalah $5.060 / \mathrm{kg}$ dengan rata-rata penerimaan sebesar Rp. 27.270.000,00 Rata-rata penerimaan petani di Kecamatan Tukdana sebesar Rp. 27.270.000,00 dalam satu kali produksi. Dan rata-rata biaya produksi total yang dikeluarkan oleh petani adalah sebesar Rp. 9.069.792,00 dalam satu kali produksi. Sehingga rata-rata pendapatan bersih petani di Kecamatan Tukdana adalah penerimaan dikurangi total produksi, rata rata 
pendapatan bersih sebesar Rp. 18.201.208,00 dalam satu kali produksi. Sesuai dengan Tabel 3 klasifikasi rentang skor variabel pendapatan usahatani, pendapatan rata-rata petani di Kecamatan Tukdana tergolong dalam klasifikasi Sangat baik(Rp 15.001.000,00 - Rp 20.000.000,00).

Data yang diolah berdasarkan data yang diperoleh dari lapangan dengan perhitungan masing masing dalam skala $1 \mathrm{Ha}$, terdapat pada tabel berikut.

Tabel 3 kekuatan hubungan (korelasi) antara variabel kinerja kelompok tani dengan pendapatan

\begin{tabular}{clcc}
\hline No. & \multicolumn{1}{c}{ Nama Kelompok } & Kinerja & Keuntungan \\
\hline 1 & Tengah Mekar & 350 & $20,953,000$ \\
2 & Gempol & 245 & $17,189,000$ \\
3 & Sri Murni 3 & 310 & $18,957,000$ \\
4 & Panca Kerta & 310 & $18,183,000$ \\
5 & Sri Murni 2 & 340 & $21,598,479$ \\
6 & Dewi Sri & 340 & $17,617,662$ \\
7 & Karang Moncol & 310 & $17,213,000$ \\
8 & Mekar Jaya & 320 & $19,905,000$ \\
9 & Ranca Bango & 335 & $17,885,437$ \\
10 & Suka Mukti & 245 & $16,125,714$ \\
\hline & & & $18,562,729$ \\
\hline
\end{tabular}

Berdasarkan analisis diatas diperoleh angka koefisien korelasi sebesar 0,678**. Artinya tingkat kekuatan hubungan (korelasi) antara variabel kinerja kelompok tani dengan pendapatan adalah sebesar 0,678 atau kuat. Melihat dari signifikansi hubungan kedua variabel berdasarkan output di atas, Dengan nilai sebesar 0,678 dapat menggambarkan sejauhmana keeratan hubungan antara variabel kinerja kelompok tani dengan pendapatan usahatani padi sawah dengan nilai 67,8\%. Jadi hubungan antara kinerja kelompok tani dengan pendapatan padi sawah di Kecamatan Tukdana Kabupaten Indramayu dapat dinyatakan positif maka hubunganya searah

\section{IV.KESIMPULAN}

\section{Simpulan}

1. Kinerja kelompok di Kecamatan Tukdana Kabupaten Indramayu sudah cukup baik, sebagian besar kinerja kelompok tani adalah tergolong klasifikasi cukup dengan skor 246 - 455, yaitu 8 kelompok tani sudah tergolong klasifikasi cukup dan 2 kelompok tani tergolong klasifikasi kurang $(\leq 245)$.

2. Hasil dari analisis diperoleh angka koefisien korelasi sebesar 0,678. Artinya tingkat kekuatan hubungan (korelasi) antara variabel kinerja kelompok tani

3. dengan pendapatan adalah kuat $(0,600-0,799)$. Dengan nilai sebesar 0,678 dapat menggambarkan sejauhmana keeratan hubungan antara variabel kinerja kelompok tani dengan pendapatan usahatani padi sawah dengan nilai $67,8 \%$. Jadi hubungan antara kinerja kelompok tani dengan pendapatan padi sawah di Kecamatan Tukdana Kabupaten Indramayu dapat dinyatakan positif maka hubunganya searah.

\section{Saran}

Berdasarkan simpulan dari penelitian ini maka disarankan, dapat ditingkatkan lagi kinerjanya agar masuk kedalam kategori madya maupun utama. Hal ini dapat didorong dengan dukungan pemerintah melalu PPL setempat.

\section{Ucapan Terima Kasih}

Ucapan Terimaksih saya ucapkan kepada Fakultas Pertanian dan LPPM UNWIR yang telah membantu dalam penelitian ini Sehingga penelitiian dengan judul "Hubungan Kinerja Kelompok Tani 
Dengan Pendapatan Usahatani Padi Sawah (Oryza Sativa, L.) Di Kecamatan Tukdana, Kabupaten Indramayu, Tahun 2017" dapat terlaksana dengan baik.

\section{DAFTAR PUSTAKA}

Adjid, D. A. 2001, Penyuluhan Pertanian. Jakarta(ID): Yayasan Sinar Tani.

Ahmadi. 2001. Ilmu Usaha Tani. Jakarta: Penebar Swadaya

Allen, P. dan D. van Dusen. 1988. Sustainable Agriculture: Choosing the Future. In Global Perspective on Agroecology and Sustainable Agriculture Systems. USA: Universiy of California.

BPS (Badan Pusat Statistik ). 2017. Kecamatan Tukdana Dalam Angka 2017. Indramayu: BPS (Badan Pusat Statistik ) Kabuaten Indramayu.

Balai Penyuluh Pertanian (BPP) Kecamatan Tukdana. 2018. Penyuluh Pertanian Tahun 2018. Kecamatan Tukdana Kabupaten Indramayu. Indramayu

Daniel, M. 2004. Pengantar Ekonomi Pertanian. Jakarta (ID): PT.Bumi Aksara

Departemen Pertanian, 2000, Modul Manajemen Peyuluhan Pertanian, Jakarta: Badan pengembangan SDM dan penyuluhan Pertanian Pusat pengembangan Petugas pertanian.

Dermawan Wibisono. 2001. Riset Bisnis Edisi Pertama. Yogyakarta (ID) : BPFE.

Dinas Pertaian. 2015. Penyuluhan Pertanian. Dinas Pertanian Kabupaten Indramayu.

Garcia, J.G. dan L. Soelistianingsih. 1998. "Why Do Differences in Provincial Income Persist in Indonesia?”. Bulietin of Indonesian Economic Studies 34 (1) : 95 - 120.

Karto. 2015. Statistik Non Parametrik. Yogyakarta (ID): K-Media.

Kementrian Pertanian. 2007. Strategi inovasi dan teknologi pertanian dalam menghadapi perubahan iklim global. Jakarta (ID).

Kementrian Pertanian. 2018. Pedoman Penilaian Kemampuan Kelompok Tani. Badan Penyuluh dan Pengembangan SDM Pertanian. Pusat Penyuluh Pertanian. Jakarta (ID).

Khazanani, A. 2011. Analisis Efisiensi Penggunaan Faktor-faktor Produksi Usahatani Cabai Kabupaten Temanggung (Skripsi) [internet]. [2018 juni 25]: Semarang. Universitas Diponegoro.

Kusnadi. 2000. Akutansi Keuangan Menengah (Intermediate) (Prinsip, Prosedur, dan Metode). BPEE

Mangkunegara, dan Prabu. 2000. Managemen Sumber Daya Manusia Perusahaan. Cetakan Ke-2. Bandung (ID): PT. Remaja Rosda Karya.

Meier, G.M. dan J.E. Rauch. 2000. Leading Issue in Ekonomics Development (seven edition). NewYorkOxford (US): Oxford University Press.

Mounder,A.H. 1972. Agricultural Extention. A Reference Manual. Food and Agriculture Organization. The United Nation. Roma 
Muljarijadi bagdja. 2011. Pembangunan Ekonomi Wilayah Pendekatan Analisis Tabel Input-Output. Bandung(ID): UNPAD PRESS.

Nasri. 2013. Peranan Kelompok Tani Dalam Meningkatkan Kesejahteraan Masyarakat Desa Ulujangang Kecamatan Bontolempangan Kabupaten Gowa. [2018 Maret 25]: Gowa. http://repositori.uinalauddin.ac.id/3668/1/Nasri.

Nazir, Mohammad. 2011. Metode Peneitian. Ghalia Indonesia.

Pane E,Y. 2017. “Hubungan partisipasi anggota dengan kinerja kelompok tani”. Fakltas Ilmu Social dan Ilmu Politik. Universitas Lampung. Bandar Lampung.

Peterson J.Larry. 2003. Oral and Maxillofacial Surgery, 4th ed, The C.V Mosby Company, St.Louis, pp:116-117.

Pusat Penyuluhan Pertanian. 1996. Penyuluhan Pertanian tahun 1996. Indramayu.

Ramirez, A., G. Ranis, and F. Stewart. 1998. "Economic Growth and Human Capital". QEH Working Paper No. 18.

Republik Indonesia. 1999. Undang-Undang No. 22 Tahun 1999 Tentang Otonomi Daerah. Jakarta(ID): Direkrorat Jenderal Perimbangan Keuangan.

Soekartawi. 1995. Pembangunan Pertanian. Raja Grafindo Persada.

Soekartawi. 2002. Analisis Usahatani. Jakarta(ID): Universitas Indonesia.

Suharyono dan Busyra BS. 2016. Kinerja Kelompok Tani Dalam Sistem Usaha Tani Padi dan Metode Pemberdayaannya. Balai pengkajian teknologi pertanian (BPTP) Jambi [internet]. [2018 juni 3]; Volume 18, nomer 1, hal 78-85: Jambi.

Suradisastra, K. 2008. Strategi Pemberdayaan Kelembagaan Petani. Forum Penelitian Agro Ekonomi. [2008 Desember]; Volume 26 No. 2, 82-91.

Sugiyono. 2012. Memahami Penelitian Kualitatif’. Bandung (ID): ALFABETA.

Syahyuti. 2007. Kebijakan Pengembangan Gabungan Kelompok Tani (GAPOKTAN) Sebagai Kelembagaan Ekonomi Di Perdesaan. Jurnal Analisis Kebijakan Pertanian.

Syahyuti. 2009. Strategi dan Tantangan Dalam Pengembangan Gabungan Kelompok Tani (Gapoktan) Sebagai Kelembagaan Ekonomi Di Pedesaan. Pusat Analisis Sosial Ekonomi dan Kebijakan Pertanian. Bogor

Wahyuni. 2009. Integrasi Kelembagaan di Tingkat Petani: Optimalisasi Kinerja Pembangunan Pertanian.Tabloid Sinar Tani 